\title{
ATIVIDADE MICROBIANA DO SOLO EM RESPOSTA A DIFERENTES FONTES DE FÓSFORO EM CULTIVO SOLTEIRO DE PASTAGEM E CONSORCIAÇÃO COM LEGUMINOSAS
}

Caroline Honorato Rocha ${ }^{1}$, Amarildo Francisquini Junior ${ }^{1}$, Daniele Perreti Bettio ${ }^{1}$, Carlos Sérgio Tiritan', Douglas Celestino Junior', Fernando Vinicius Bressan'1, Amanda Aline Azevedo da Silva', Tiago Aranda Catuchi', Juliano Carlos Calonego ${ }^{2}$

${ }^{1}$ Universidade do Oeste Paulista - UNOESTE, Presidente Prudente; SP. ${ }^{2}$ Universidade Estadual Paulista UNESP, Botucatu, SP. E- mail: honorato-carol@hotmail.com

\section{RESUMO}

Objetivou-se com esse trabalho avaliar por meio de análises microbiológicas do solo as mudanças ocasionadas no sistema através da adoção da consorciação de mombaça com leguminosas (java e feijão - guandu), sob a influência de diferentes fontes de fósforo (Bayóvar e SFT). O experimento foi conduzido na Fazenda experimental da Universidade do Oeste Paulista - UNOESTE. Para a realização das análises microbiológicas foram coletadas amostras de solo na profundidade de 0 $10 \mathrm{~cm}$, sendo elas: biomassa microbiana, respiração basal do solo e atividade da enzima desidrogenase. No consorcio solteiro com adubação de $\mathrm{N}$ o fertilizante bayóvar proporcionou uma maior taxa de biomassa microbiana e respiração do solo.

Palavras - chave: Mombaça. Sistemas integrados. Java. Guandú. Microorganismos.

\section{SOIL MICROBIAL ACTIVITY IN RESPONSE TO DIFFERENT SOURCES MATCH IN PASTURE MONOCROP AND INTERCROPPING WITH PULSES}

\begin{abstract}
The objective of this study was to evaluate through microbiological soil analyzes the changes caused in the system by adopting intercropping of Mombasa with legumes (java and beans pigeon pea), under the influence of different sources of phosphorus (Bayóvar and SFT). The experiment was conducted at the experimental farm of the University of West Paulista - UNOESTE. To carry out the microbiological analysis of soil samples were collected in the $0-10 \mathrm{~cm}$, which are: microbial biomass, soil respiration and activity of dehydrogenase enzyme . In consortium with single $\mathrm{N}$ fertilization Bayóvar the fertilizer provided a higher rate of microbial biomass and soil respiration .
\end{abstract}

Keywords: Mombasa. Integrated system. Java. Guandu. Microorganisms. 


\section{INTRODUÇÃO}

Atualmente diferentes tipos de sistemas de cultivos vêm sendo adotados para melhorar a qualidade das plantas e do solo. Dentre eles temos como destaque a consorciação entre leguminosas e gramíneas que já demonstrou bons resultados em estudos a campo, pois as leguminosas forrageiras podem ser utilizadas como uma alternativa na melhoria de pastagens degradadas cultivadas em regiões tropicais (CARVALHO, PIRES; 2008). Portanto, fica evidente que o aumento da produtividade das pastagens consorciadas minimizam os impactos no sistema de cultivo e melhoram a qualidade do solo, além de que, o maior rendimento animal irá reduzir a emissão de gases causadores do efeito estufa (VILELA et al., 2005).

Entretanto, quando se pensa em consórcio de gramíneas com leguminosas forrageiras para se obter resultados satisfatórios tem que levar em consideração a adoção adequada dos cultivares de acordo com as condições ambientais, as disponibilidades de recursos, dentre outros fatores, considerando também que existe uma resistência por parte dos produtores em função do insucesso dos custos envolvidos (BARCELLOS et al., 2008).

Atualmente existem receios por parte dos produtores em se adotar a prática de consorciação, porém se deve enfatizar e mensurar a eficiência desse tipo de sistema, demonstrando o potencial de melhoria ocasionado com o uso de leguminosas no sistema de cultivo, pois elas aumentam a disponibilidade de fósforo ( $P$ ) para as gramíneas através da acidificação gradual da rizosfera liberando $\mathrm{H}+$, aumentando a solubilização de $\mathrm{P}$ da fonte natural reativa e a absorção do mesmo pela forrageira (SANTOS et al., 2001), além dessa vantagem outro nutriente que também é disponibilizado através da ação das leguminosas é o nitrogênio ( $N$ ), fornecido por meio da fixação biológica o que responderá significativamente pela manutenção da produtividade da pastagem (BARCELLOS et al., 2008).

Além do aporte de $\mathrm{P}$ e $\mathrm{N}$, a atividade biológica do solo é favorecida em ambientes consorciados, sendo que podem ser vistas melhorias a mais tais como, aumento da capacidade de armazenamento de água no solo, diminuição de erosões, ciclagem de nutrientes, quebra do ciclo de patógenos e consequentemente maior período produtivo da pastagem (BARCELLOS et al., 2008).

Dentre as espécies vegetais propícias ao consórcio se tem o capim mombaça (Panicum maximum Jacq.), considerado uma das forrageiras tropicais mais produtivas, pois apresenta alta resposta à adubação fosfatada (GHERI et al., 2000). E dentre as de mais leguminosas temos o Java (Macrotyloma axillare), uma planta vigorosa e eficiente em nodulação sendo indicada para consórcios (PAIVA et al., 2008). Outra espécie com potencial para consorciação é o feijão guandu (Cajanus cajan L.), que possui enorme potencial para exercer múltiplas funções no sistema de produção agrícola, além de gerar produtos de elevados valores biológicos melhorando o meio ambiente (AZEVEDO et al., 2007).

Para se obter o sucesso esperado na consorciação, experimentos com diferentes fontes minerais de adubações devem ser levados em consideração, com isso fontes de $P$ vêm sendo acompanhadas no desenvolvimento que promove às culturas. Dentre elas o Superfosfato Triplo (SFT) se mostrou eficiente em promover disponibilidade de $P$ às plantas nos primeiros ciclos de cultivo seguidos à sua aplicação, isto é, estamos nos referindo a uma fonte de liberação imediata (RAMOS et al., 2009) e paralelamente se tem o Bayóvar, fonte com disponibilização gradual de $P$ no solo (CAIANO et al., 2013).

Portanto, o presente trabalho teve como objetivo avaliar por meio de análises microbiológicas do solo as mudanças ocasionadas no sistema através da adoção da consorciação de mombaça com leguminosas (Java e Feijão - guandu), sob a influência de diferentes fontes de fósforo (Bayóvar e SFT). 


\section{METODOLOGIA}

O experimento foi conduzido na Fazenda Experimental da Universidade do Oeste Paulista UNOESTE, em Presidente Bernardes - SP. O solo desta área é caracterizado como argissolo vermelho distroférrico, no qual apresenta um maior acúmulo de argila em profundidade (horizonte b) maior do que na camada superficial do solo (EMBRAPA 2006). O clima da região, segundo a classificação de Koppen é do tipo Cwa, onde as temperaturas médias são de 25 o C es índices pluviométricos variam em determinadas épocas do ano, sendo o verão mais chuvoso e o inverno mais seco.

O delineamento experimental utilizado foi em blocos casualizados em esquema fatorial $4 \times 3$ em parcela subdividida, com quarto repetições. As parcelas foram constituídas por quatro sistemas de forragem: mombaça (Panicum maximum cv. Mombaça) solteira com ausência de adubação nitrogenada de cobertura; mombaça solteira com adubação nitrogenada de cobertura (150 kg ha-1 de $\mathrm{N}$ ano- ${ }^{-1}$ ); mombaça consorciada com Java (Macrotyloma axilare cv. ) e mombaça consorciada com feijão - guandu anão (Cajanus cajan). As subparcelas foram compostas pelas seguintes adubações: ausência de adubação fosfatada; com fonte solúvel (super fosfato triplo); aplicação de adubação fosfatada com fonte natural reativa (fosfato natural Bayóvar) e adubação nitrogenada com a fonte de ureia $\left(45 \%\right.$ N). Cada parcela se constituiu por uma área de $3750 \mathrm{~m}^{2}$, já as subparcelas possuíam $937 \mathrm{~m}^{2}$.

$\mathrm{Na}$ área foi realizada uma caracterização química do solo e com isso se realizou a correção de acidez e a adubação fosfatada conforme a recomendação técnica. Assim sendo, foram aplicados 2 t ha-1 de calcário dolomitico e 1 t ha-1 de gesso agrícola para o fornecimento de enxofre.

Para a realização das análises microbiológicas foram coletadas amostras de solo na profundidade $0-10 \mathrm{~cm}$. A análise da biomassa microbiana foi determinada pelo método descrito por Vance, Brook e Jenkinson (1987), utilizando-se, em lugar do clorofórmio, a irradiação proporcionada por forno de microondas. Este procedimento denominado de irradiação-extração (IE) foi adaptado por Ferreira, Camargo e Vidor (1999). Os valores do carbono presente na biomassa microbiana ( $\mathrm{C}$ mic) foram calculados pela equação $\mathrm{Cmic}(\mathrm{MG} \mathrm{Kg}-1)=(\mathrm{Cl}-\mathrm{CNI}) / \mathrm{Kec}$, onde $\mathrm{Cl}$ é o carbono extraído da amostras de solo irradiada, $\mathrm{CNI}$ é o carbono extraído da amostra de solo não irradiada e o Kec é fator de correção do carbono microbiano = 0,21 (FRIGHETTO, 2000).

A análise de respiração do solo seguiu a metodologia da retenção de $\mathrm{CO} 2$ na solução de Hidróxido de sódio ( $\mathrm{NaOH}$ ). Para medição do carbonato de sódio formado se utilizou o método condutimétrico com leituras de condutividade na solução de $\mathrm{NaOH}$ após 24 e 48 horas, empregando-se um condutivímetro modelo HI99301 (Hanna instruments) (RODELLA; SABOYA, 1999). A quantidade de CO2 produzida pela respiração foi calculada a partir da fórmula e os resultados foram expressos em mg de C-CO2g-1 h-1.

A atividade da enzima desidrogenase foi realizada pelo método descrito por Casida et al., (1964), com algumas modificações descritas a seguir. Foram adicionados $2 \mathrm{ml}$ da solução de TTC (cloreto de 2,3,5 - trifeniltetrazólio) a $1 \%$ e $1 \mathrm{ml}$ de glicose a 0,1\% em 5 gramas de solo de cada amostra em tubos de vidro, em seguida realizou-se uma homogeneização das amostras e prosseguiu para incubação por 18 horas em estufa a $370 \mathrm{C}$ no escuro. Após o tempo estipulado, foram adicionados $9 \mathrm{ml}$ de metanol em cada amostra para ocorrer a extração do TTC reduzindo a trifenil formazan (TTF). Realizou-se filtragem com papéis filtros de liberção lenta e o líquido coletado foi lido em espectrofotômetro com absorbância em $530 \mathrm{~nm}$. Os resultados foram expressos em $\mu \mathrm{g}$ TTF g- ${ }^{1}$ de solo 18 horas.

Os dados foram submetidos á análise de variância e os valores médios foram comparados através do teste de Tukey $(p<0,05)$, utilizando-se o programa estatístico SISVAR (FERREIRA, 2000). 


\section{RESULTADOS}

De acordo com a análise de variância (Tabela 01) a análise de respiração não demonstrou resultado significativo para as médias dos valores obtidos de acordo com os diferentes consórcios. Assim, também pode se observar que não houve valores significativos nas fontes de $P$ e na interação entre os fatores na análise da enzima desidrogenase.

Tabela 01. Análise de variância e coeficiente de variação para as análises microbiológicas de um solo submetido a diferentes consórcios e fontes de fósforo.

\begin{tabular}{|c|c|c|c|}
\hline & $\begin{array}{l}\text { Biomassa Microbiana } \\
\text { (mg C Kg- }{ }^{-1} \text { solo) }\end{array}$ & $\begin{array}{c}\text { Respiração } \\
\left(\mathrm{mg} \mathrm{CO}_{2} \mathrm{~g}^{-1} \text { solo } \mathrm{h}^{-1}\right)\end{array}$ & $\begin{array}{c}\text { Desidrogenase } \\
\left(\mu \mathrm{g} \text { TTF g- }{ }^{1} 18 \mathrm{~h}^{-1}\right)\end{array}$ \\
\hline Consórcios & $*$ & $\mathrm{Ns}$ & $*$ \\
\hline Fontes de $\mathrm{P}$ & $* *$ & $* *$ & Ns \\
\hline Cons. $x$ Fontes ${ }^{1}$ & $* *$ & $* *$ & Ns \\
\hline $\mathrm{CV}^{2}$ & 17,57 & 12,64 & 16,07 \\
\hline
\end{tabular}

${ }^{1}$ Interação entre os fatores anteriormente citados; ${ }^{2} \mathrm{CV}=$ coeficiente de variação (\%); ns, ${ }^{* *} \mathrm{e}^{*}=$ não significativo, significativo a $1 \%$ e $5 \%$ de probabilidade respectivamente.

Observando a Tabela 02, a biomassa microbiana aumentou no consórcio com feijão guandu sem adubação fosfatada. Já, o fertilizante bayóvar elevou a quantidade de carbono microbiano e diferiu entre o cultivo de mombaça sem nitrogênio e o consórcio com java, sendo este último inferior. Em relação aos consórcios que receberam SFT, o cultivo solteiro da forrageira isenta de adubação nitrogenada apresentou baixo valor na quantidade de biomassa microbiana, igualando por sua vez ao consórcio com guandu.

Em relação às fontes de adubações fosfatadas o fertilizante bayóvar apresentou maiores incrementos na biomassa microbiana quando não se aplicou $\mathrm{N}$ na mombaça e se destacou igualando aos resultados estatísticos ao SFT no consórcio com java. Ressalta-se ainda que quando não aplicou nenhuma adubação de fósforo nos tratamentos os dados diferiram dos demais com aumento apenas no consórcio com guandu.

Tabela 02. Desdobramento entre a interação dos fatores em estudo para os resultados da análise de biomassa microbiana do solo representados em $\mathrm{mg} \mathrm{C} \mathrm{Kg-}^{1}$ solo.

\section{FONTES DE FÓSFORO}

\begin{tabular}{lccc}
\hline \multirow{2}{*}{ CONSÓRCIOS } & \multicolumn{3}{c}{ FONTES DE FÓSFORO } \\
\cline { 2 - 4 } & Sem P & Bayóvar & SFT \\
\hline Mombaça sem N & $81,59 \mathrm{bB}$ & $121,46 \mathrm{aA}$ & $71,03 \mathrm{cB}$ \\
Mombaça com N & $61,89 \mathrm{bC}$ & $93,68 \mathrm{abB}$ & $131,75 \mathrm{aA}$ \\
Mombaça + Java & $58,80 \mathrm{bB}$ & $88,71 \mathrm{bA}$ & $106,97 \mathrm{abA}$ \\
Mombaça + Guandu & $128,03 \mathrm{aA}$ & $97,83 \mathrm{abB}$ & $91,71 \mathrm{bcB}$ \\
\hline
\end{tabular}

Letras minúsculas são referentes aos valores das colunas e letras maiúsculas aos valores das linhas. Letras iguais não se diferem ao Teste de Tukey ao nível de $5 \%$ de probabilidade.

Ao analisar-se a interação dos fatores sobre a respiração microbiana do solo houve diferenças significativas no consórcio com o fertilizante superfosfato triplo (SFT), onde o cultivo solteiro com nitrogênio e o sistema de consórcio com guandu apresentou uma maior taxa de respiração em relação ao tratamento sem $\mathrm{N}$ (Tabela 03). 
Assim como a biomassa foi elevada quando se adubou o cultivo solteiro sem $\mathrm{N}$ com bayóvar, o mesmo ocorreu com a taxa respiratória, demonstrando de tal forma que a maior quantidade de microrganismos resultou em alto valor de respiração microbiana. Quando comparamos novamente os dados da biomassa no tratamento com $\mathrm{N}$ o fertilizante SFT apresentou maior atividade microbiana, já que tem alta quantidade de biomassa e consequentemente maior liberação de CO2.

Tabela 03. Interação entre os fatores em estudo para os resultados de respiração basal microbiana do solo (mg de $\mathrm{C}-\mathrm{CO}_{2} \mathrm{~g}^{-1}$ solo $\mathrm{h}^{-1}$ ).

\begin{tabular}{lccc}
\hline \multirow{2}{*}{ consóRCIOS } & \multicolumn{3}{c}{ FONTES DE FÓSFORO } \\
\cline { 2 - 4 } & Sem $\mathrm{P}$ & Bayóvar & SFT \\
\hline Mombaça sem N & $6,42 \mathrm{aB}$ & $8,03 \mathrm{aA}$ & $6,07 \mathrm{bB}$ \\
Mombaça com N & $5,75 \mathrm{aB}$ & $6,63 \mathrm{aB}$ & $8,29 \mathrm{aA}$ \\
Mombaça + Java & $5,67 \mathrm{aA}$ & $6,85 \mathrm{aA}$ & $6,67 \mathrm{abA}$ \\
Mombaça + Guandu & $7,08 \mathrm{aA}$ & $7,11 \mathrm{aA}$ & $7,76 \mathrm{aA}$ \\
\hline
\end{tabular}

Letras minúsculas são referentes aos valores das colunas e letras maiúsculas aos valores das linhas. Letras iguais não se diferem ao Teste de Tukey ao nível de $5 \%$ de probabilidade.

As utilizações de diferentes consórcios nos ambientes de cultivos de pastagem associada com distintas fontes de adubações fosfatadas apresentam resultados que devem ser estudados por maior período de tempo, já que podem interferir em atributos microbiológicos do solo e refletir nos dados de produções do sistema.

\section{DISCUSSÃO}

Segundo Brito et al. (2014) o sistema Milho + fósforo apresentou 14,2 na taxa de C-CO2 e 30,1 na qCO2 $(p<0,05)$ sendo os maiores valores em relação aos demais sistemas de manejo avaliados. O sistema Milho + Guandu + fósforo favoreceu o maior incremento do Carbono da biomassa microbiana do solo e um acúmulo significativo de $\mathrm{C}$ no solo, enquanto o sistema com milho solteiro não favoreceu o desenvolvimento da comunidade microbiana. De acordo com Souza et al. (2010) a alta intensidade de pastejo (baixa altura da pastagem, $10 \mathrm{~cm}$ ) pode provocar redução no $\mathrm{C}$, no $\mathrm{N}$ e no $\mathrm{P}$ da biomassa microbiana e aumento na respiração microbiana do solo sob condições de estresse hídrico.

Quanto maior a quantidade de raízes, aliado ao corte da parte aérea, que provoca alta exsudação de compostos orgânicos (TISDALL; OADES, 1982), maior é o favorecimento da biomassa microbiana do solo, que utiliza esses compostos como fonte de $C$, porém no experimento de Xavier et al. (2006) o uso de consórcio entre gramíneas e leguminosas não acarretou na aumento da biomassa microbiana do solo.

Assim como a biomassa microbiana apresentou uma maior quantidade quando foi adubado com o fertilizante fosfatado, (Brookes et al., 1982) relata que, após a aplicação de fosfato o aumento de $P$ na biomassa microbiana representa uma forma eficiente de armazenagem desse nutriente, sendo os microrganismos essenciais na biociclagem e armazenagem de $P$.

No trabalho realizado por (Serrão et al., 2006) descreve que a maior taxa de biomassa microbiana se apresenta no sistema fósforo e nitrogênio + fósforo, mostrando que a atividade microbiana tem melhor resposta na presença da adubação fosfatada. 


\section{CONCLUSÃO}

O fertilizante bayóvar comparado com os demais tratamentos aumentou a quantidade de carbono microbiano no solo e elevou a respiração basal do solo devido a maior quantidade de microrganismos.

\section{REFERENCIAS}

AZEVEDO, R.L.; RIBEIRO, G. T.; AZEVEDO, C. L. L. Feijão Guandu: Uma Planta Multiuso. Revista da Fapese, v.3, n.2, p. 81-86, 2007.

BARCELLOS, A. O.; RAMOS, A. K. B.; VILELA, L.; MARTHA JUNIOR, G. B. Sustentabilidade da produção animal baseada em pastagens consorciadas e no emprego de leguminosas exclusivas, na forma de banco de proteína, nos trópicos brasileiros. Revista Brasileira de Zootecnia., v.3, p.51-67, 2008. https://doi.org/10.1590/S1516-35982008001300008

BRITO, M.F. Atributos Microbiológicos e Fauna Invertebrada Epigeica do Solo em cultivo de Milho Consorciado com leguminosas. Caderno de Agroecologia, v.9, n.4, 2014.

BROOKES, P.C.; POWLSON, D.S. \& JENKINSON, D.S. Measurement of microbial biomass phosphorus in soil. Soil Biol. Biochem, v.14, p.319-329, 1982. https://doi.org/10.1016/00380717(82)90001-3

CAIONE, G.; FERNANDES, F.M.; LANGE, A. Efeito residual de fontes de fósforo nos atributos químicos do solo, nutrição e produtividade de biomassa da cana-de-açúcar. Revista Brasileira de Ciências Agrárias, v.8, p.189-196, 2013. https://doi.org/10.5039/agraria.v8i2a2016

CARVALHO, G. G. P. E PIRES, A. J. V. Leguminosas tropicais herbáceas em associação com Pastagens. Archivos de zootecnia, v.57, p. 104, 2008.

CASIDA, G; KLEIN, D. SANTORO, T. Et. Al. Soil Dehydrogenase Activity. Ciência do Solo, v.98, p.371376, 1964.

FRIGHETTO, R.T.S. Análise da biomassa microbiana em carbono: método de fumigação-extração, 2000.

FERREIRA, D. F. Análise estatística por meio do SISVAR para Windows versão 4.0. In:Reunião anual da região brasileira da sociedade internacional de biometria, v. 45, p. 255-258, 2000.

GHERI, E.O.; CRUZ, M.C.P.; FERREIRA, M.E. Nível crítico de fósforo no solo para Panicum maximum Jacq. cv. Tanzânia.Pesquisa Agropecuária Brasileira, v.35, n.9, p.1809-1816, 2000. https://doi.org/10.1590/S0100-204X2000000900013

PAIVA, A. S.; RODRIGUES, T. J. D.; CANCIAN, A. J.; LOPES, M. M. de; FERNANDES, A. C. Qualidade física e fisiológica de sementes da Leguminosa Forrageira Macrotyloma axillare cv. Java. Revista Brasileira de Sementes, v. 30, n. 2, p. 130-136, 2008. https://doi.org/10.1590/S0101$\underline{31222008000200016}$

TISDALL, J.M. \& OADES, J.M. Organic matter and waterstable aggregates in soil. J. Soil Sci., v.33, p.141-163, 1982. https://doi.org/10.1111/j.1365-2389.1982.tb01755.x 
RAMOS, S.J.; FAQUIN, V.; RODRIGUES, C.R.; SILVA, C.A.; BOLDRIN, P.F. Biomass production and phosphorus use of forage grasses fertilized with two phosphorus sources. Revista Brasileira de Ciência do Solo, v.33, p.335-343, 2009. https://doi.org/10.1590/S0100-06832009000200011

RODELLA, A. A.; SABOYA, L. V. Calibrations for conductimetric determination of carbon dioxide. Soil biology and Biochemistry, Oxford, v. 31, n. 14, p.2059-2060, 1999.

SANTOS, A. B.; FAGERIA, N. K.; SILVA, O.F.; MELO, M. L. B. Resposta do feijoeiro ao manejo de nitrogênio em várzeas tropicais. Pesquisa Agropecuária Brasileira, v.38, n. 11, p.1265-1271, 2003. https://doi.org/10.1590/S0100-204X2003001100003

SERRÃO, B.O.; CARVALHO, C.J.R.; DUTRA, F.C.; Mecanismos ligados a ciclagem de nitrogênio e fósforo em áreas de pastagem abandonada na Amazônia Oriental: Resultados de um experimento de fertilização. IV Seminário de Iniciação Científica da UFRA e X Seminário de Iniciação Científica da EMBRAPA Amazônia Oriental, 2016.

SOUZA, E.D.; Costa, S.E.V.G.A.; ANGHINONI, I.; LIMA, C.V.S.; CARVALHO, P.C.F.; MARTINS, A.P.; Biomassa microbiana do solo em sistemas de integração lavoura-pecuária em plantio direto, submetido a intensidades de pastejo. Revista Brasileira Ciência do solo, v.34, p.79-88, 2010. https://doi.org/10.1590/S0100-06832010000100008

VANCE, E.D.;BROOKS, P.C.; JENKINSON,D.S. An extraction method for measuring soil microbial biomass. Soil Biologic \& Biochemistry, v. 19, n. 6, p.703-707,1987. https://doi.org/10.1016/0038$\underline{\text { 0717(87)90052-6 }}$

VILELA, L.; MARTHA JR., G.B.; BARIONI, L.G.; BARCELLOS, A.O.; ANDRADE, R.P. Pasture degradation and long-term sustainability of beef cattle systems in the Brazilian Cerrado. XIX Annual Meeting of the Society for Conservation Biology Conservation Biology Capacity Building \& Practice in a Globalized World, 2005.

XAVIER, F.A.S.; MAIA, S.M.F.; OLIVEIRA, T.S.; MENDONÇA, E.S.; Biomassa microbiana e matéria orgânica leve e solo sob sistema agrícola regânico e convencional na Chapada da Ibiapaba - CE, Revista Brasileira. Ciência do Solo, 2006. 